\title{
Perfurações de cupins e geomorfogênese em arenitos paleozoicos da região dos Campos Gerais do Paraná
}

\section{Termite galleries and geomorphogenesis in Paleozoic sandstones of the Campos Gerais region, Paraná state, southern Brazil}

\section{Mario Sérgio de Melo}

\begin{abstract}
RESUMO
A região dos Campos Gerais do Paraná notabiliza-se pela ocorrência de arenitos paleozoicos da Bacia do Paraná (Formação Furnas e arenitos do Grupo Itararé), os quais apresentam feições de relevo singulares, entre elas canyons, escarpamentos, relevos ruiniformes, furnas, lagoas, depressões, alvéolos, sumidouros, túneis, etc. Tais feições têm importância por encerrarem importante patrimônio natural com valor ambiental, científico, econômico, educacional e para o lazer, e por influenciarem no regime dos mananciais subterrâneos. Estas feições indicam que alguns dos arenitos constituem carste não carbonático. É comum a ocorrência de perfurações tubulares de diâmetro subcentimétrico a centimétrico, associadas a muitas das feições de relevo, sugerindo influência recíproca. As perfurações podem ter origem na ação de processos de erosão mecânica e/ou química (alvéolos, túneis de dissolução) ou de organismos (cupins, raízes). Observações sistemáticas destas perfurações indicam que elas são de diferentes idades. Algumas das mais recentes são inequivocamente atribuíveis a cupins, pela presença de cupinzeiros vivos, ou pela preservação de características morfológicas típicas. À medida que são mais antigas e desfeitas pelo intemperismo, a origem das perfurações torna-se mais incerta. Este trabalho procura organizar a descrição das perfurações em arenitos da região. A verossímil hipótese de que parte delas tenha estreita relação com a atividade de cupins traz a necessidade de se reconsiderar este fator, usualmente negligenciado no estudo da origem e evolução de feições erosivas e cavidades subterrâneas.
\end{abstract}

Palavras-chave: Arenitos paleozóicos; Perfurações de cupins; Relevo ruiniforme; Geoformas em arenitos.

\begin{abstract}
The Campos Gerais region in the Paraná State, Southern Brazil, shows extent exposures of Paleozoic sandstones of the Paraná Sedimentary Basin (Furnas Formation and sandstones of the Itararé Group). These rocks develop singular landforms, such as canyons, escarpments, ruiniform reliefs, furnas (collapsed hollows), ponds, depressions, alveoli, sinkholes, tunnels, etc. Such features contain important natural patrimony with environmental, scientific, economic, ecotouristic and educational value and influence groundwater dynamics. They indicate that some of the sandstones form noncarbonate karst systems. Tubular perforations with subcentimetric to centimetric diameter are commonly associated with erosive landforms, suggesting a reciprocal influence. The perforations may be provoked by the action of mechanical and/or chemical erosion (alveoli, dissolution tunnels) or organisms (termites, roots). Systematic observations of these perforations indicate they are from different time periods. Some of the newer ones are clearly attributable to termites, due to the presence of active mounds or the preservation of typical morphological features. As they become older and shattered by weathering, the origin of the perforations becomes more uncertain, some of them believed as the result of ancient termite galleries. This paper aims to organize the description of sandstone perforation in the region. The plausible hypothesis of strict correlation between perforations and the activity of termites brings the need to reassess this factor, usually overlooked in the study of the origin and evolution of surface and underground erosion features.
\end{abstract}

Keywords: Paleozoic sandstones; Termite galleries; Ruiniform relief; Sandstone landforms.

\section{Introdução}

A influência das perfurações de cupins tem sido apontada tanto no desenvolvimento de solos lateríticos, crostas ferruginosas e minérios de bauxita como na origem de importantes sistemas de canais nos solos e rochas, encontrados ao se escavar o sítio de construção da fundação de grandes barragens (Taltasse 1957, Machado 1983a,b e 1987, Grassé 1986, Martins \& Leonardos 1992). Fontes \& Vulcano (1998) relatam 
várias dessas situações e descrevem o concrecionamento dos túbulos fósseis de antigos cupinzeiros por enriquecimento com derivados de ferro, o que ajuda a preservar a geometria original das perfurações.

Na região dos Campos Gerais do Paraná, onde existem extensas exposições de arenitos paleozoicos da Bacia do Paraná, as perfurações de cupins aparecem associadas a feições erosivas típicas, entre elas os chamados relevos ruiniformes do Parque Estadual de Vila Velha, no município de Ponta Grossa.

Os fatores responsáveis pela evolução das feições erosivas dos arenitos paleozoicos são de múltipla natureza: atributos das rochas sedimentares, falhas e fraturas, ação das águas meteóricas, da radiação solar e de macro e microrganismos, entre outros.

O papel das perfurações de cupins no singular modelado de relevo da região é usualmente menosprezado. Entretanto, em várias situações é possível observar notável perfuração dos arenitos por cupins, algumas vezes em situações que fazem supor que a idade dos túbulos possa ser bastante antiga. Outras vezes observam-se feições erosivas associadas a perfurações onde a provável ação de cupins não é nítida. Mas elas podem ter evoluído a partir dos túbulos, o que torna o estudo de suas relações oportuno, quando se visa analisar o papel relativo dos diversos fatores envolvidos na gênese das feições típicas dos arenitos paleozoicos da região.

\section{Os Campos Gerais do Paraná}

A região dos Campos Gerais do Paraná (figura 1), cuja conceituação vem se modificando ao longo do tempo, foi originalmente definida como a borda do Segundo Planalto Paranaense, no reverso do degrau topográfico representado pela Escarpa Devoniana, tal qual denominada por Maack (1981). Ali, uma conjugação de fatores ambientais - envolvendo climas (atual e pretéritos), tipos de solo, altitude e a existência de barreiras naturais à dispersão de sementes propiciou a preservação de vegetação dominante de campos, que outrora dominou a paisagem paranaense (Maack 1948, 1981, Behling 1997).

Além da vegetação típica que empresta seu nome à região, os Campos Gerais destacam-se pelo relevo movimentado onde sobressaem a Escarpa Devoniana, o Canyon do Guartelá e outros sítios singulares: arroios em leito rochoso, cachoeiras, matas-galerias, impressionando os viajantes e pesquisadores por sua beleza e riqueza paisagística (Saint-Hilaire 1978).

No sentido de Maack (1948), que define os Campos Gerais com base em critérios naturais, a região compreende 11.761,41 km² (Melo et al. 2007a), estendendo-se por 22 municípios da região centro-leste do Estado do Paraná, desde Rio Negro, a sul, no limite com Santa Catarina, até Sengés, a norte, no limite com São Paulo.

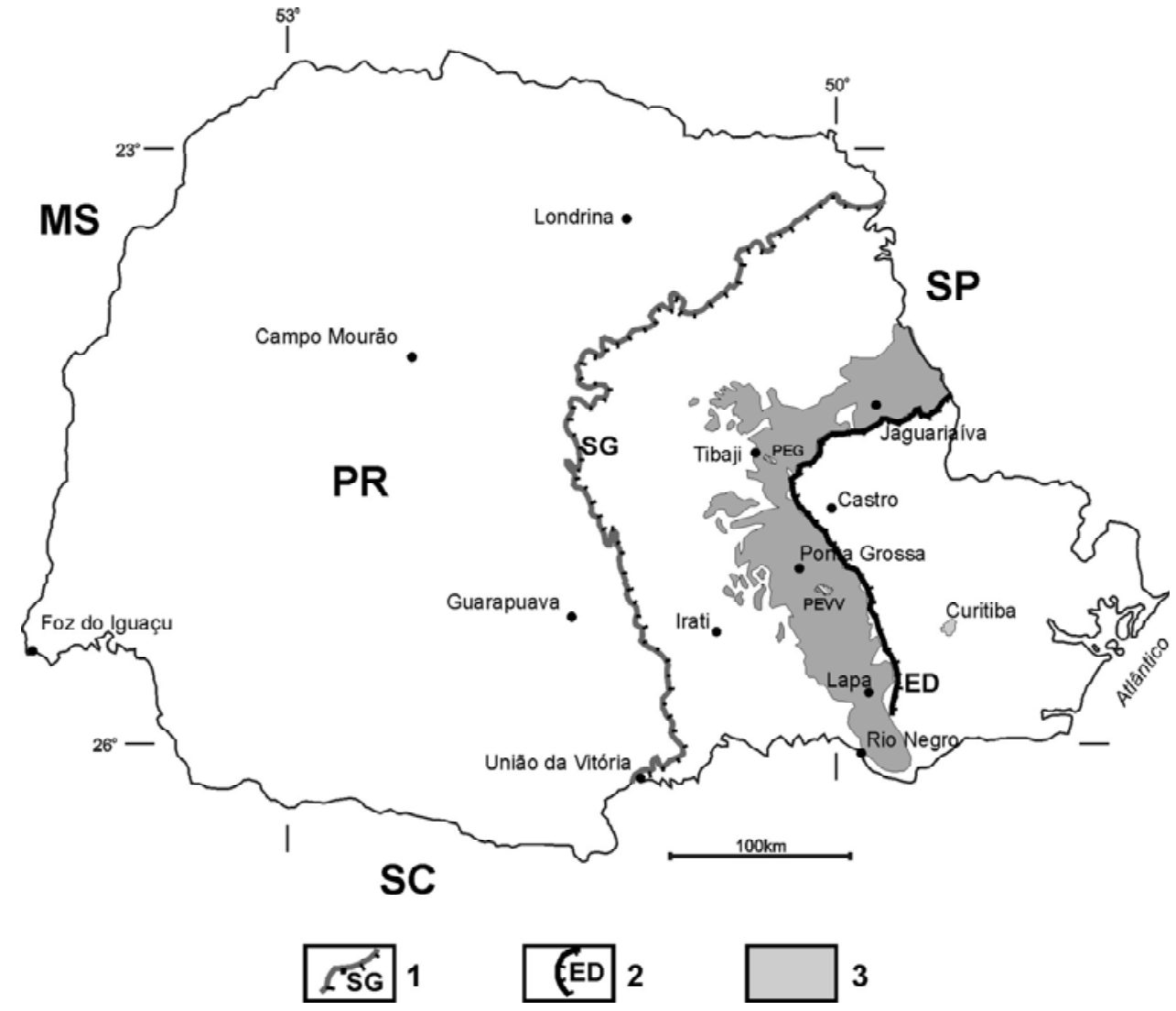

Figura 1: Localização dos Campos Gerais do Paraná. 1: Serra Geral; 2: Escarpa Devoniana; 3: Extensão original dos campos naturais no Segundo Planalto Paranaense; PEVV: Parque Estadual de Vila Velha; PEG: Parque Estadual do Guartelá (baseado em Maack 1948 e Mineropar 1989) 


\section{Os arenitos dos Campos Gerais do Paraná}

Os principais arenitos dos Campos Gerais pertencem à Formação Furnas e ao Grupo Itararé (figura 2). A Formação Furnas (ou Arenito Furnas), de idade silurodevoniana, é formada quase que exclusivamente por quartzo arenitos médios a grossos de coloração clara, relativamente homogêneos, com grãos angulosos a subangulosos. A típica coloração clara é devida à presença da caulinita e ilita como cimento dos grãos de quartzo e feldspato. As estruturas sedimentares (estratificação planoparalela e cruzada, contatos entre camadas submétricas a até $5 \mathrm{~m}$ de espessura) são marcantes. Os arenitos da Formação Furnas sustentam o degrau topográfico representado pela Escarpa Devoniana e são a unidade geológica dominante no reverso da escarpa.

O Grupo Itararé foi depositado entre o Carbonífero Superior e o Permiano, em vários subambientes de um ambiente glacial dominante. Nele ocorrem diversos tipos rochosos (diamictitos, ritmitos, argilitos), entre eles arenitos, sendo alguns dos mais conhecidos na região os denominados Arenito Lapa, que ocorrem próximo à cidade homônima, e o Arenito Vila Velha, que aparece no Parque Estadual de Vila Velha, notório pelos relevos ruiniformes. O Arenito Vila Velha é constituído essencialmente de quartzo, mostrando evidências de dissolução, neoformação e cimentação por óxidos de ferro e manganês, esta desenvolvida durante fenômenos ocorridos muito tempo após a sedimentação (Maack 1946, Melo 2006).

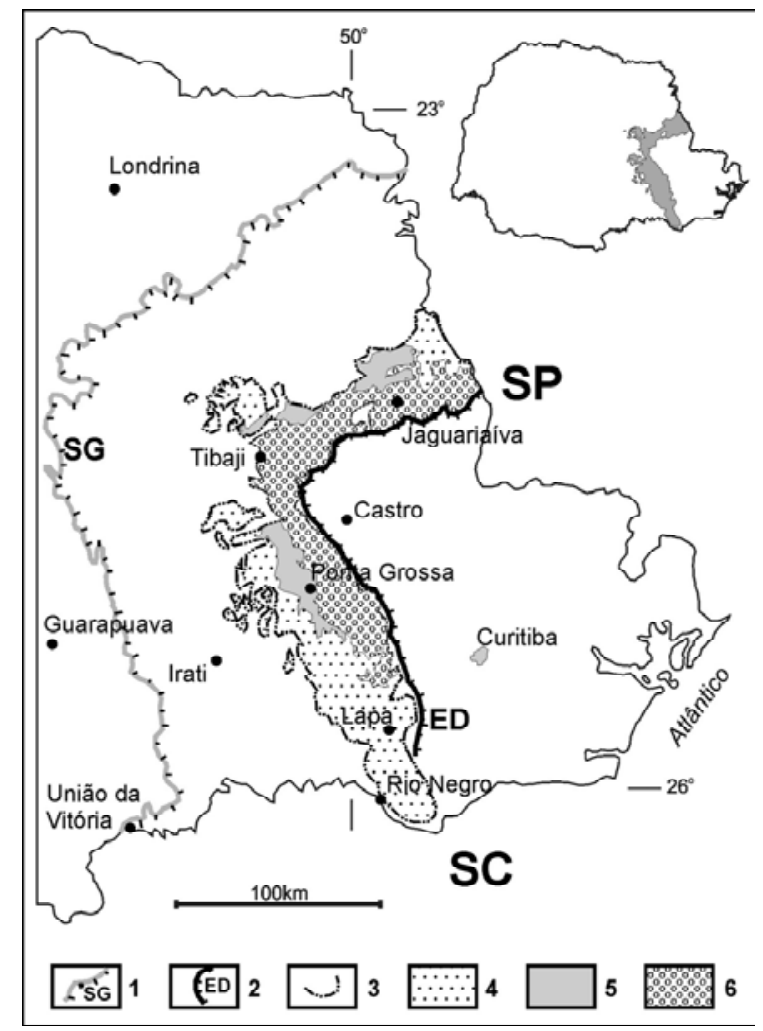

Figura 2: Contextualização regional dos Campos Gerais do Paraná. 1: Serra Geral; 2: Escarpa Devoniana; 3: Limites dos Campos Gerais; 4: Grupo Itararé; 5: Formação Ponta Grossa; 6: Formação Furnas (baseado em Maack 1948 e Mineropar 1989)

\section{Feições de relevo nos arenitos dos Campos Gerais}

Os principais tipos de feições de relevo observáveis nos arenitos dos Campos Gerais, segundo Melo (2006) e Melo et al. (2007b), são:

- escarpamentos: penhascos verticalizados, sustentados principalmente pelos arenitos da Formação Furnas e ocasionalmente do Grupo Itararé;

- morros testemunhos: elevações com topo aplainado, sustentadas por rochas relativamente mais resistentes à erosão, como é o caso do Arenito Vila Velha;

- relevos ruiniformes (ruiniform landscapes): a expressão tem sido utilizada no Brasil desde a década de 1960 (Ab’Sáber 1968), e ganhou projeção internacional após sua utilização na região de Roraima, no sul da Venezuela (Mainguet 1972 apud Wray 1997), exibindo paisagens desfeitas, com muitos penhascos de até 1 quilômetro em ortoquartzitos proterozoicos;

- torres e pináculos: formados por erosão mecânica e/ou dissolução (intemperismo químico do cimento ferruginoso ou caulinítico e de grãos de feldspato e quartzo, seguido de remoção mecânica dos grãos);

- cavernas, dolinas de dissolução (depressões úmidas e secas), sumidouros, vales secos: feições típicas de relevos cársticos, ou seja, onde a dissolução é processo importante na elaboração das formas; embora sejam feições típicas de rochas carbonáticas, ocorrem também nos arenitos dos Campos Gerais, principalmente na Formação Furnas, onde o cimento caulinítico sofre dissolução com mais facilidade, configurando-se carste não carbonático (Melo \& Giannini 2007, Melo et al. 2011);

- fendas, corredores e labirintos: alargamento de juntas que canalizam o fluxo d'água, por dissolução e erosão mecânica;

- furnas: um tipo de "poços de desabamento" (collapsed hollows), formado pelo desabamento do teto de grandes cavidades subterrâneas (Maack 1956, Soares 1989); as mais conhecidas são as furnas do Parque Estadual de Vila Velha; algumas furnas próximas ao leito de rios principais aparecem hoje na forma de lagoas, como é o caso das lagoas Dourada e Tarumã; as furnas são consideradas dolinas de abatimento;

- cachoeiras e corredeiras: quedas d'água e áreas de estrangulamento da drenagem, que sofrem influência das rochas pouco sujeitas ao intemperismo (arenitos cimentados) e estruturas (falhas, diques, fraturas, acamamento);

- lapas: abrigos formados por tetos naturais protegendo reentrâncias rochosas, estas formadas por diversos processos (erosão mecânica, dissolução, etc.); comumente são sítios arqueológicos (v.g. Silva et al. 2006, 2007);

- entalhes de base de paredes rochosas (solution notches, entalhes basais, covas de pé-de-escarpa): 
formam-se onde solos bordejam superfícies rochosas verticais, aparentemente em consequência de processos de alteração associados à percolação de águas de infiltração e do solo; a base dos rochedos torna-se côncava;

- caneluras ou canaletas (runnels, karren, lapiés, gutter, rills): pequenas feições e canais de drenagem em rocha formados por dissolução e/ou erosão mecânica diretamente pelas águas meteóricas;

- bacias de dissolução (solution basins, grammas, weathering pans, pits, opferkessel, rock tanks): pequenas depressões em rocha com fundo aplainado, atribuídas à dissolução dominante, pela ação de águas pluviais estagnadas; podem coalescer ou interligar-se por canaletas;

- alvéolos (tafoni): escavações superficiais promovidas pelas águas pluviais, por ação de erosão mecânica e dissolução;

- túneis anastomosados e cones de erosão: feições originadas por erosão mecânica e dissolução, controladas por juntas horizontais;

- juntas poligonais: abertura, por efeito de dissolução/erosão mecânica, de juntas poligonais formadas aparentemente pela insolação;

- perfurações produzidas por cupins: perfurações em rochas, sobretudo arenitos, atribuídas a cupins (tubos termíticos); a origem é interpretada pelos padrões construtivos (geometria, orientação, diâmetro).

As feições de relevo em arenitos na região dos Campos Gerais têm grande importância, ainda não satisfatoriamente compreendida e aproveitada pela população e poder público locais (Melo et al. 2011). As feições que aparecem na superfície do terreno (canyons, escarpamentos, lagoas, furnas, relevos ruiniformes, etc.) constituem sítios de extrema beleza e singularidade paisagística, que só localmente têm seu valor (subjetivo, científico, econômico, educacional, ambiental) reconhecido, como acontece nos parques estaduais de Vila Velha e do Guartelá, por exemplo. Além de se prestarem a atividades de lazer (ecoturismo, turismo de aventura) e esportivas (esportes na natureza), estes sítios constituem microecossistemas com espécies endêmicas de grande potencial científico e para a realização de atividades de educação para a sustentabilidade. Ademais, podem ensejar a criação de empregos em atividades econômicas sustentáveis, como o ecoturismo e os esportes na natureza.

As feições subterrâneas, cuja existência é sugerida por feições vistas na superfície (furnas, lagoas, depressões, fendas, túneis anastomosados, etc.), têm importância no fluxo das águas subterrâneas, em uma região com crescente demanda de recursos hídricos, paralelamente a um risco de contaminação que aumenta com o uso de agrotóxicos e lançamento de efluentes (Melo 2009).

\section{Fatores que influenciam nos processos e feições erosivas}

Podem-se relacionar alguns fatores intrínsecos principais, ou seja, próprios das rochas, que influenciam a evolução e a forma final das feições de relevo típicas dos arenitos dos Campos Gerais. Entre eles, a textura, o cimento e as estruturas sedimentares e rúpteis.

Os aspectos texturais controlam a possibilidade de percolação de fluidos na rocha, interferindo nos processos de cimentação e neoformação, durante a diagênese, e de intemperismo e erosão, durante a alteração.

O Arenito Furnas, como já visto, apresenta cimento de argilominerais (caulinita e ilita) de origem diagenética.

O Arenito Vila Velha apresenta cimento constituído sobretudo por óxidos de ferro, subordinadamente manganês. Tal cimentação é irregular, ora na forma de película envolvendo os grãos, ora obliterando totalmente o espaço entre os grãos. Essa irregularidade é, em parte, o motivo da variação de resistência das diferentes camadas desse arenito aos processos erosivos (erosão diferencial), resultando nas saliências e reentrâncias que aparecem nas paredes e formas rochosas.

As estruturas controlam a possibilidade de percolação de fluidos através da rocha, interferindo na cimentação, no intemperismo e erosão, e finalmente na elaboração das feições resultantes desses processos. Em algumas situações observa-se também que as estruturas controlam a atividade biológica (crescimento de liquens, raízes, perfurações de cupins).

Os fatores extrínsecos dos processos erosivos são aqueles exteriores às rochas, que influenciam a natureza e a intensidade da erosão. Os principais são o relevo, as águas das chuvas, a radiação solar e os organismos.

A situação dos Campos Gerais, no reverso da Escarpa Devoniana, faz com que existam desníveis locais de até $450 \mathrm{~m}$ entre o Segundo e o Primeiro Planalto Paranaense. Isto determina a existência de fortes gradientes hidráulicos, bem como a tendência de abertura de juntas e fraturas, o que aumenta a velocidade dos processos erosivos.

As águas das_chuvas são, sem dúvida, o principal agente erosivo responsável pela formação das feições erosivas da região, onde atualmente chove em média $1.500 \mathrm{~mm}$ por ano.

A repetição do ciclo circadiano de radiação solar determina o fenômeno da fadiga, que é a ruptura da estrutura dos minerais e rochas. Essas rupturas, inicialmente microfissuras, vão sendo ampliadas e, pela ação da água e organismos, vão se abrindo em sulcos e caneluras próximo à superfície, dando origem às fraturas poligonais, eventualmente semelhantes ao casco de tartarugas.

Os organismos têm importante coparticipação nos processos erosivos responsáveis pela elaboração das feições de relevo dos Campos Gerais. O mais visível 
indício dessa coparticipação é fornecido pelas raízes de árvores, que penetram nas fraturas, forçando-as a se abrirem ainda mais. Plantas rupícolas de menor porte (samambaias, orquídeas, musgos, bromélias) vicejam em irregularidades dos paredões rochosos (fraturas, reentrâncias, alvéolos), ampliando-as ainda mais. Liquens, andorinhões, pássaros pretos, tatus, etc. também colaboram com os processos intempéricos inorgânicos no desenvolvimento dos processos e feições erosivos.

\section{Perfurações nos arenitos dos Campos Gerais}

Não raro observam-se perfurações nos arenitos, que podem ter origens diversas: pequenos dutos formados por processos de dissolução, ação de raízes, ação de cupins e outros organismos escavadores.

Algumas das perfurações apresentam geometria ainda bem preservada (calibre, orientação, comunicação, continuidade) que permite atribuí-las à ação de cupins. $O$ fato de nem sempre serem observados cupinzeiros atuais próximos sugere que possa tratar-se de feições relativamente antigas. A seguir, serão apresentadas perfurações atribuíveis a cupins, bem como outras de origem incerta, mas que podem também ter sido originadas a partir de antigos túbulos.

\subsection{Antiguidade das perfurações}

Alguns autores têm feito referência às idades de evidências da ação de cupins em solos e rochas. Tais idades podem variar do Cretáceo Superior (Machado 1987) ao Pleistoceno Superior (Machado 1983a, Grassé 1986) e Holoceno (Machado 1983a).

Situações observadas nos arenitos dos Campos Gerais sugerem que existem nas rochas perfurações de diversas idades. As mais antigas estão mais desfeitas pelos processos de intemperismo e incrustações (figuras 3 e 4); as mais jovens estão ainda bem preservadas (figuras 5 e 6), algumas vezes conservando o revestimento interno dos túbulos com material peletal fino (figura 7).

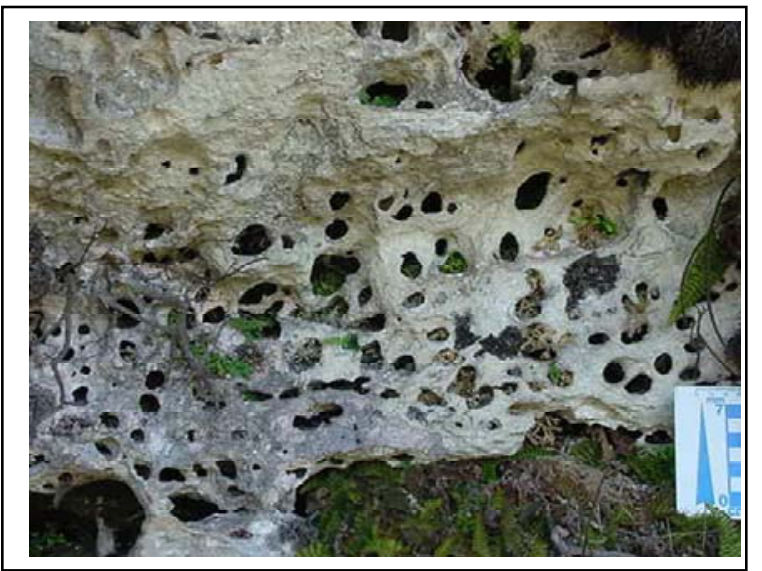

Figura 3: Perfurações atribuíveis a cupins, já desfeitas, indicando certa antiguidade. Formação Furnas na Lapa Floriano, Parque Estadual do Guartelá.

Visto ser possível, em alguns casos, coletar material dos túbulos e galerias contendo resíduos orgânicos (figuras 7 e 8), deverá também ser viável a obtenção de algumas idades para as atividades de cupins da região.

\subsection{Incrustações nas perfurações}

A precipitação de óxidos e hidróxidos de ferro nas paredes das galerias de cupins é um fenômeno bem conhecido, ligado à formação de lateritas e ferricretes (Taltasse 1957, Téssier 1959, Machado 1983b, Grassé 1986, Machado 1987).

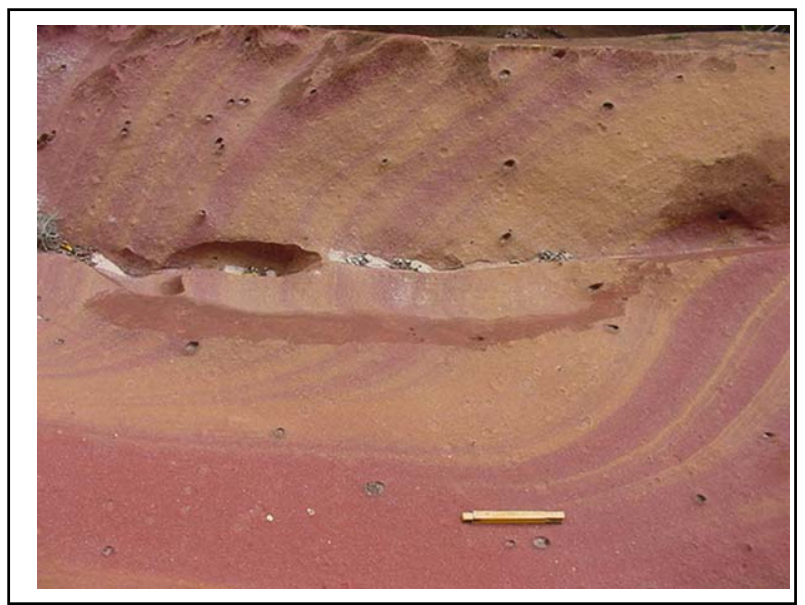

Figura 4: Perfurações com incrustação de óxido de ferro, o que indica antiguidade. Arenito Vila Velha com pseudoestratificações, Parque Estadual de Vila Velha.

Nos arenitos dos Campos Gerais observa-se incrustação por óxidos e hidróxidos de ferro tanto na Formação Furnas (figura 9) quanto no Grupo Itararé (figuras 10 e 11). Estas incrustações são mais comuns no Arenito Vila Velha, em consequência de sua característica cimentação por óxidos de ferro, mobilizados em parte graças à matéria orgânica decorrente da atividade dos cupins.

Em alguns locais, principalmente nos arenitos da Formação Furnas (figura 12), que apresenta característico cimento caulinítico, mas ocasionalmente também no Arenito Vila Velha (figura 10), os túbulos de cupins apresentam-se incrustados por material claro caulinítico.

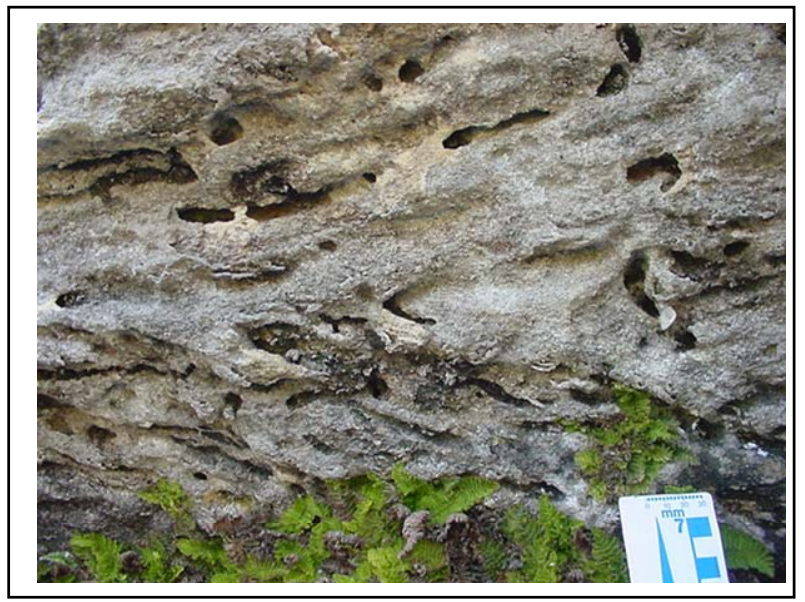

Figura 5: Perfurações de cupins melhor preservadas. Formação Furnas no Parque Estadual de Vila Velha. 


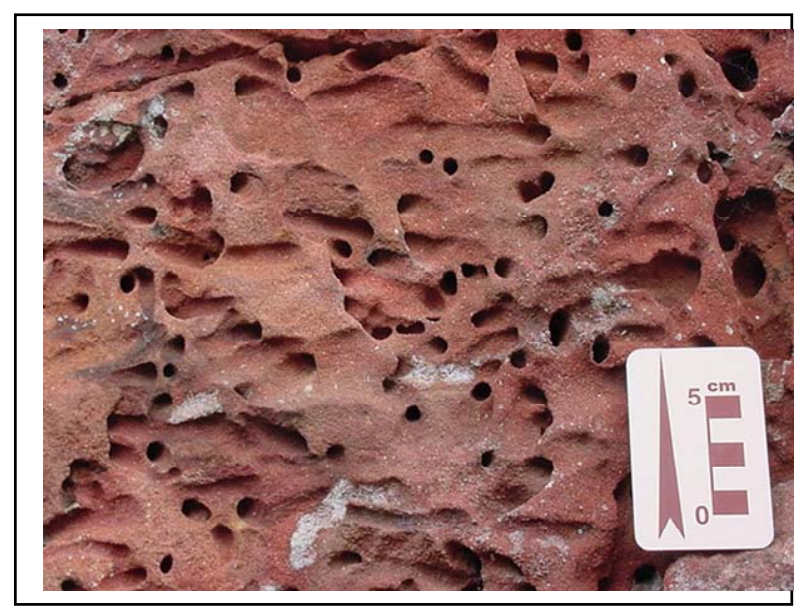

Figura 6: Perfurações de cupins recentes, bem preservadas. Arenito Vila Velha no Platô das Toquinhas, próximo ao Parque Estadual de Vila Velha.

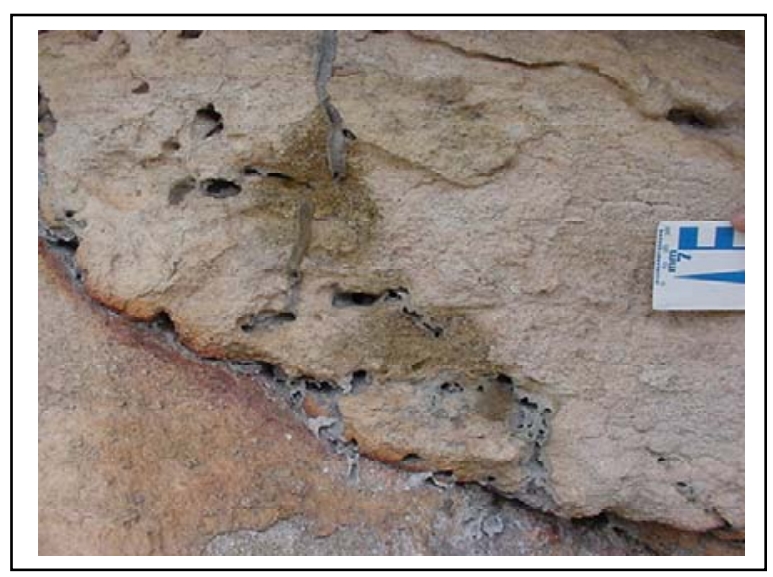

Figura 7: Perfurações de cupins atuais, com material peletal fino revestindo internamente os túbulos, em arenito pouco intemperizado da Formação Furnas. Parque Estadual do Cerrado.

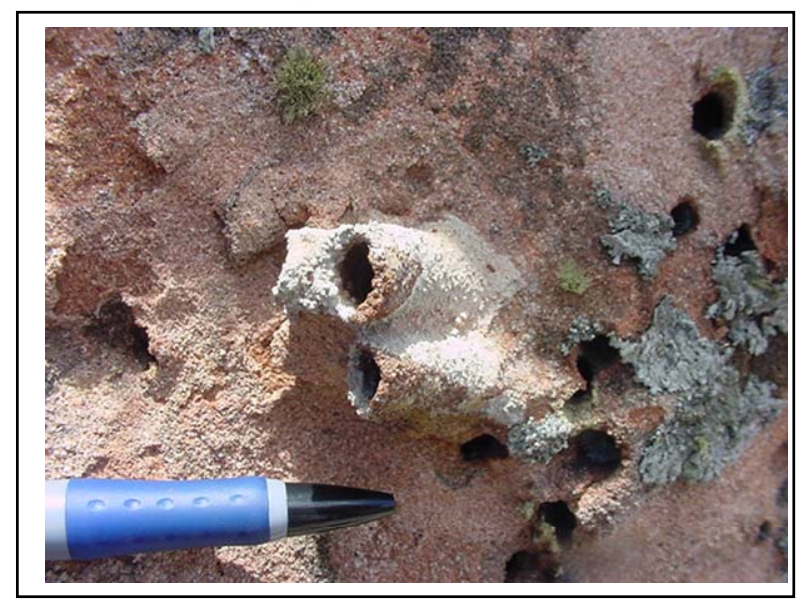

Figura 8: Perfurações de cupins recentes, com preservação parcial do material que reveste internamente os túbulos. Arenito Vila Velha no Platô das Toquinhas, próximo ao Parque Estadual de Vila Velha.

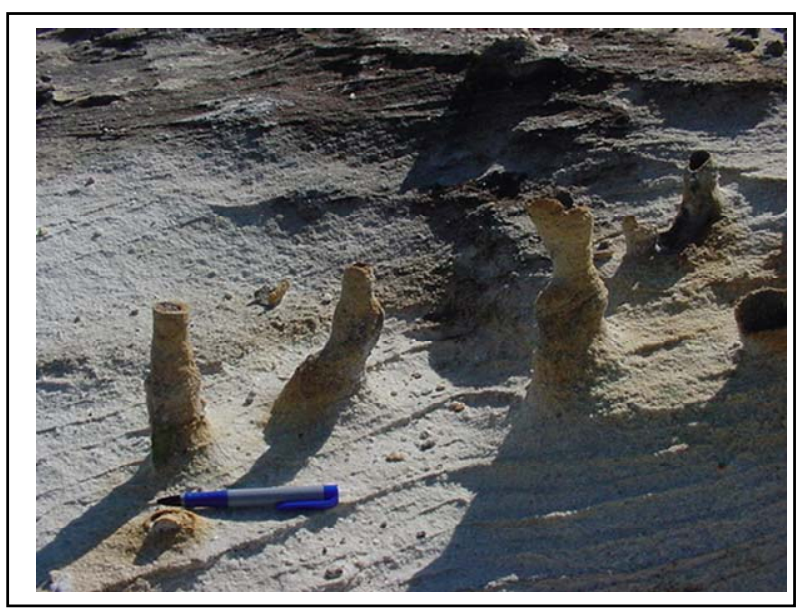

Figura 9: Incrustação de óxidos de ferro endurecendo perfurações em arenitos intemperizados da Formação Furnas. Lajeado da Lagoa, município de Piraí do Sul.

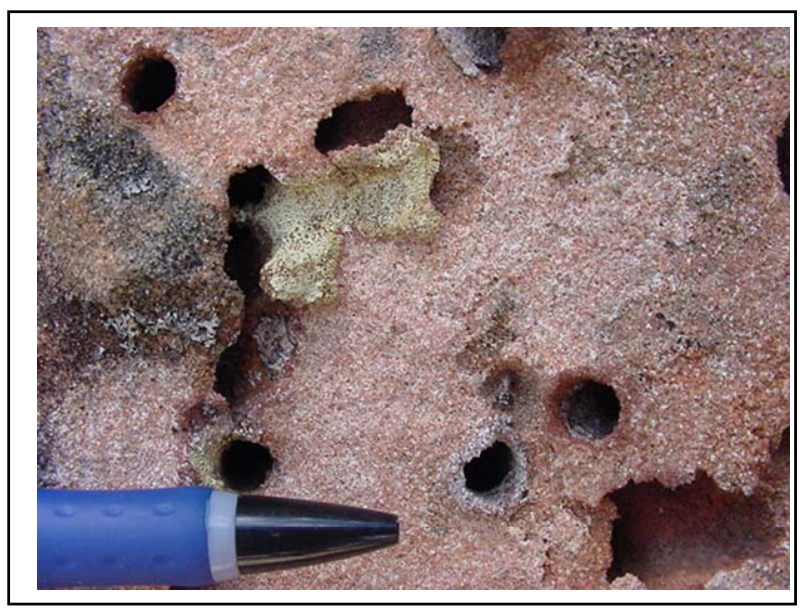

Figura 10: Incrustação de óxidos de ferro (vermelhas) e caulinita (claras) endurecendo perfurações no Arenito Vila Velha. Platô das Toquinhas, próximo ao Parque Estadual de Vila Velha.

\subsection{Controle litoestrutural das perfurações}

A distribuição não aleatória de perfurações faz supor que alguns atributos da rocha controlam a ação dos cupins. Algumas vezes, as perfurações distribuem-se preferencialmente ao longo de camadas, tanto no Arenito Furnas (figuras 13 e 14) quanto no Arenito Vila Velha. Nesses casos, possivelmente a atividade dos cupins é controlada pela textura dos arenitos (tamanho e imbricação dos grãos) e pela intensidade da cimentação por caulinita ou óxidos de ferro. Outras vezes as perfurações apresentam tendência de paralelismo com a estratificação cruzada do arenito (figura 15), cuja variação textural influencia a coesão da rocha. Outras vezes, ainda, as perfurações atribuíveis a cupins, com incrustações associadas, alinham-se ao longo de fraturas nos arenitos (figura 16). 


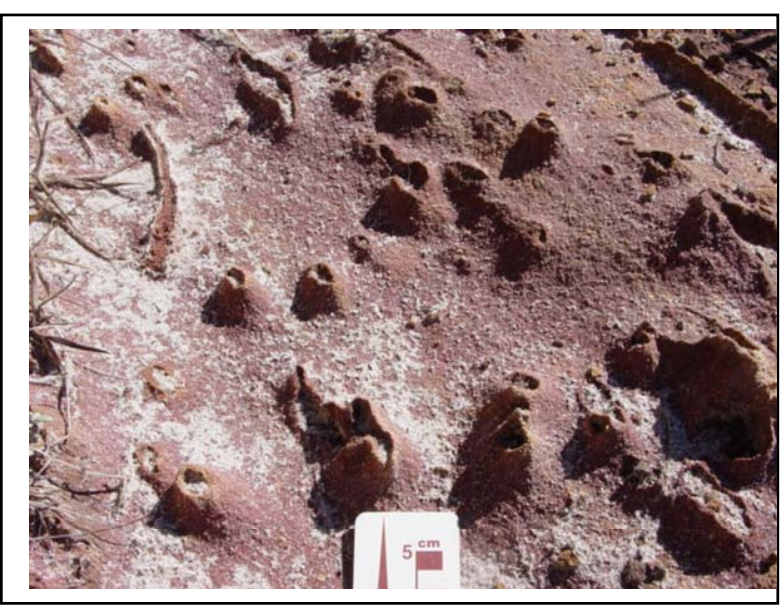

Figura 11: Incrustação de óxidos de ferro endurecendo perfurações no Arenito Vila Velha bastante intemperizado. Parque Estadual de Vila Velha.

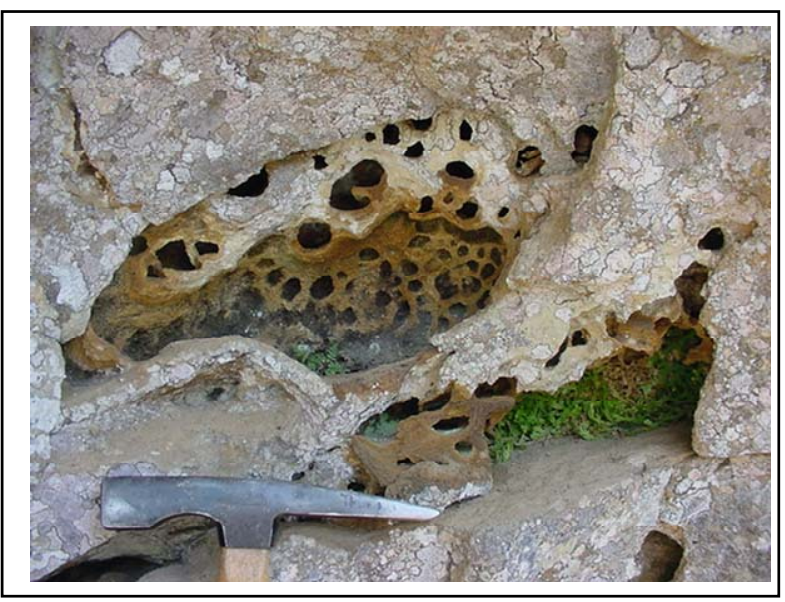

Figura 12: Incrustação de caulinita (faixas claras envolvendo túbulos) na Formação Furnas. Note-se que as perfurações associam-se a alvéolos escavados na rocha. Salto Peludo, município de Sengés.

\subsection{Intemperismo e perfurações}

Graças à cimentação - seja por caulinita e ilita, no caso da Formação Furnas, seja por óxidos de ferro no caso do Grupo Itararé -, os arenitos dos Campos Gerais são rochas bastante coesas e enrijecidas quando não alteradas, passando a materiais arenosos friáveis quando decompostas por processos intempéricos.

Entretanto, observa-se que ocorrem perfurações de cupins em rochas sãs, praticamente isentas de alteração (figuras 7 e 17), bem como em rochas já bastantes intemperizadas e relativamente friáveis (figuras 9 e 11).

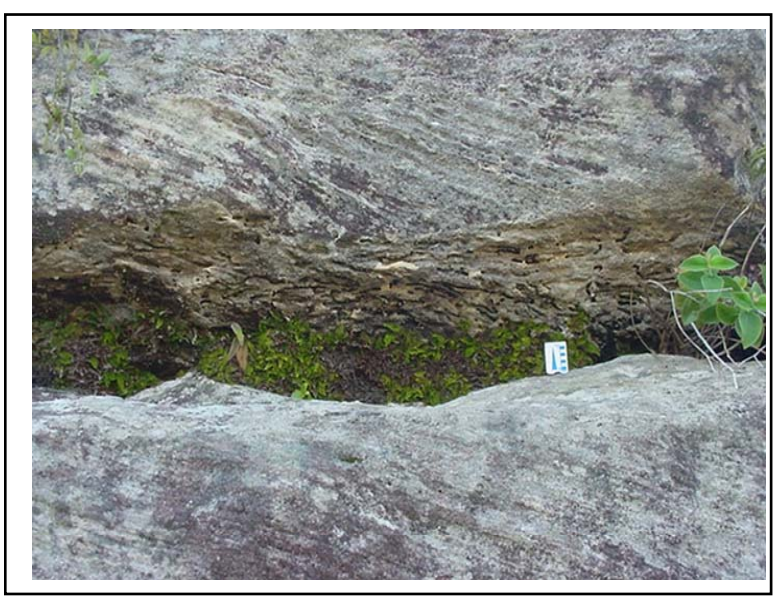

Figura 13: Perfurações recentes de cupins acompanhando camada com textura mais fina da Formação Furnas no Parque Estadual de Vila Velha. As camadas abaixo e acima, com estratificação cruzada e textura mais grossa, não apresentam perfurações.

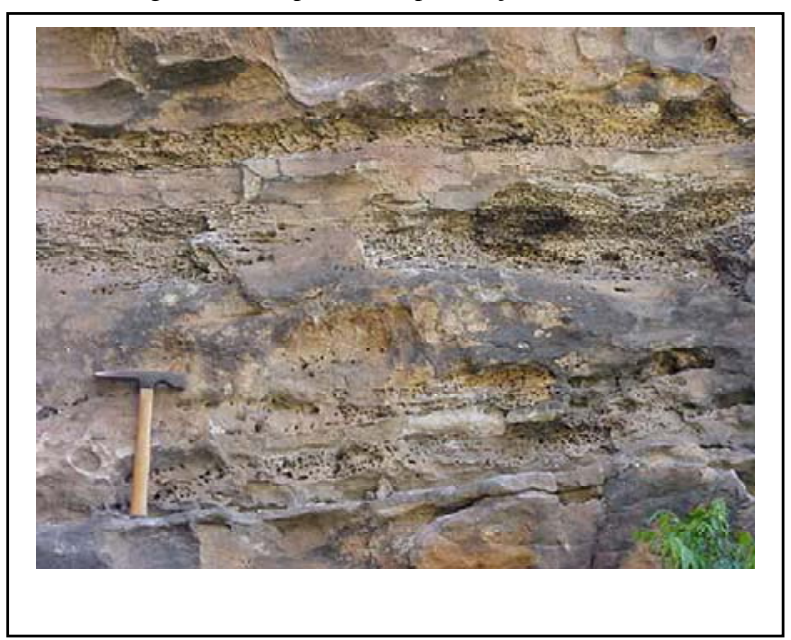

Figura 14: Perfurações de cupins acompanhando camadas da Formação Furnas. Buraco do Padre ("Favos”), município de Ponta Grossa.

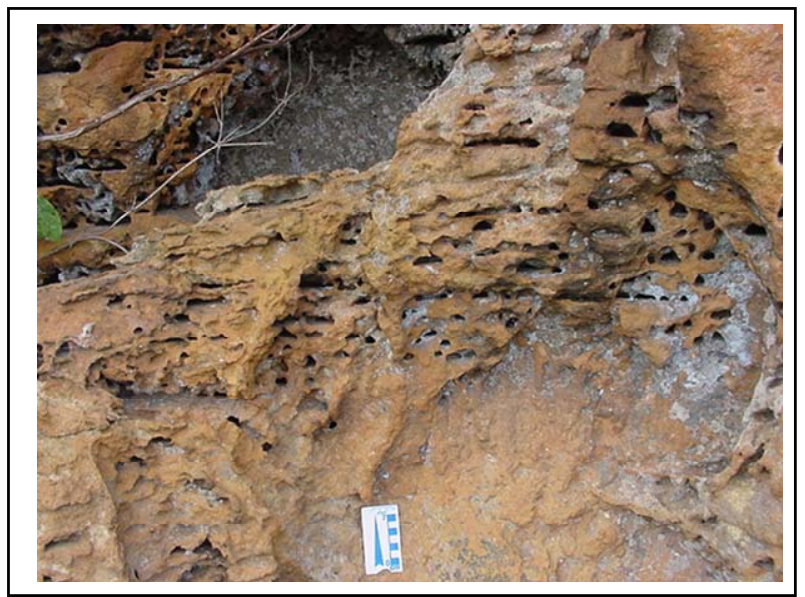

Figura 15: Perfurações atribuíveis a antigos túbulos de cupins acompanhando a estratificação cruzada do Arenito Vila Velha. Platô da Fortaleza, no Parque Estadual de Vila Velha. 


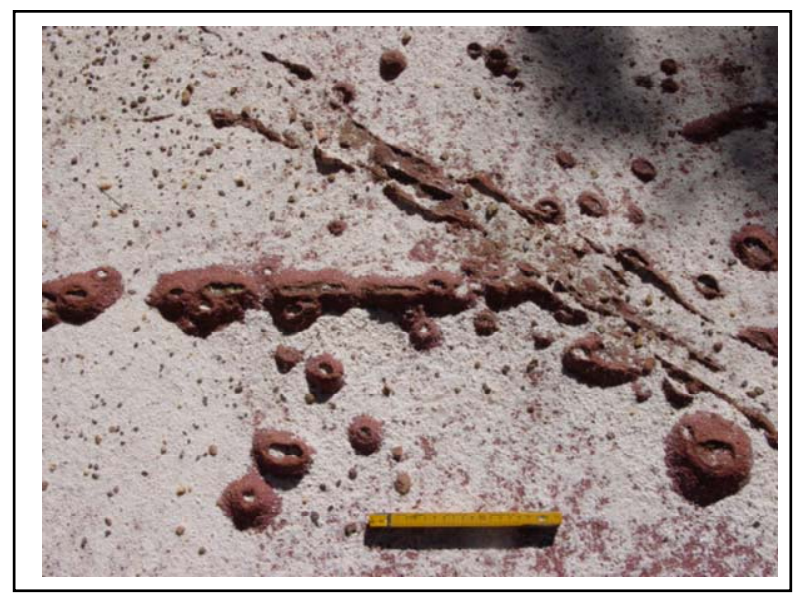

Figura 16: Perfurações antigas com incrustação de óxido de ferro acompanhando fraturas no Arenito Vila Velha, no Parque Estadual de Vila Velha.

\subsection{Perfurações e desenvolvimento de outras feições maiores}

Algumas vezes perfurações atribuíveis a cupins associam-se nitidamente a alvéolos, sugerindo relação genética entre elas (figuras 12 e 18). É possível que a alveolização evolua a partir de perfurações, onde a maior concentração de matéria orgânica, com consequente liberação de ácidos húmicos, favorece a dissolução do cimento e escavação dos alvéolos. Em algumas situações, o inverso também pode ocorrer, ou seja, os cupinzeiros instalam-se em depressões preexistentes nas rochas.

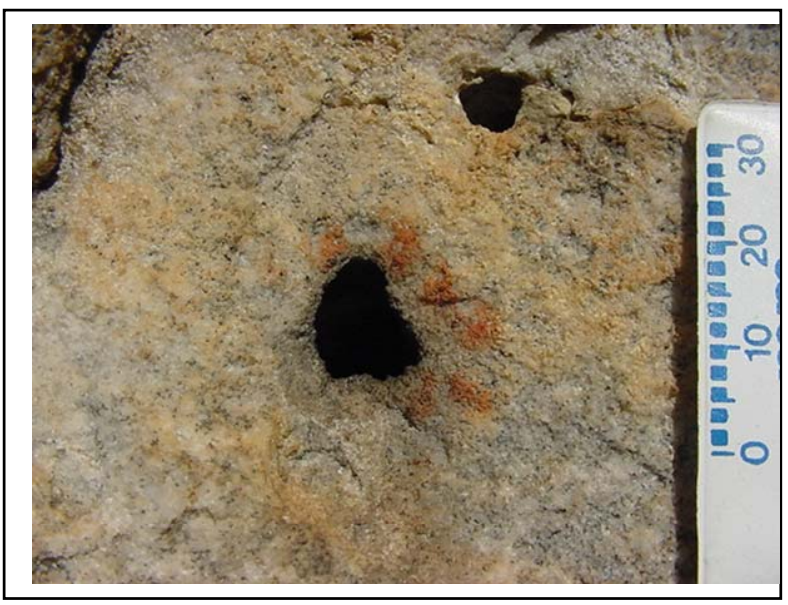

Figura 17: Perfurações atribuíveis a cupins em rocha sã da Formação Furnas, observando-se pinturas rupestres em pigmento vermelho em torno de uma das perfurações. Piraí da Serra, município de Piraí do Sul.

Outras vezes, a ocorrência de feições de cones de erosão e túneis anastomosados (figura 19), controlados por descontinuidades entre camadas dos arenitos, aparece junto a furos atribuíveis a cupins, os quais podem ter auxiliado na evolução dessas feições erosivas, embora não sejam mais claramente reconhecíveis.

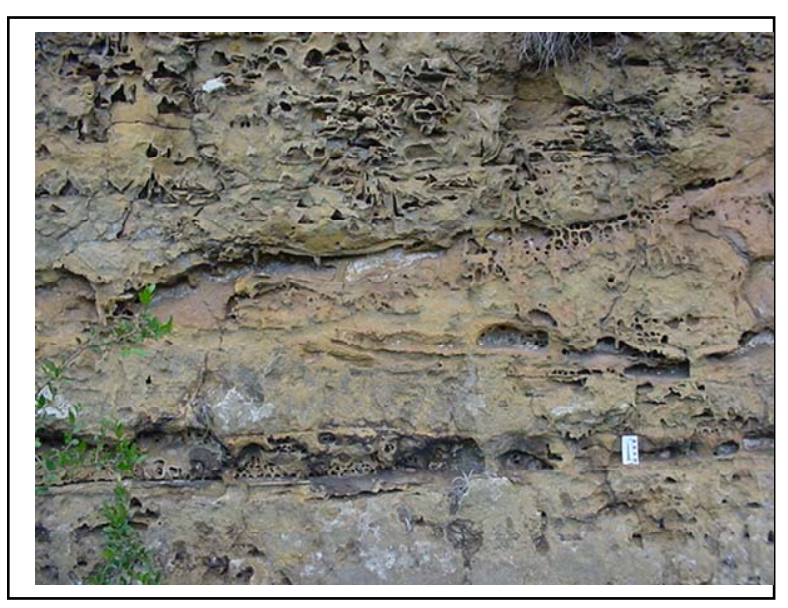

Figura 18: Intensa alveolização do Arenito Vila Velha, às vezes estreitamente associada com perfurações atribuíveis a cupins. Platô da Fortaleza, Parque Estadual de Vila Velha.

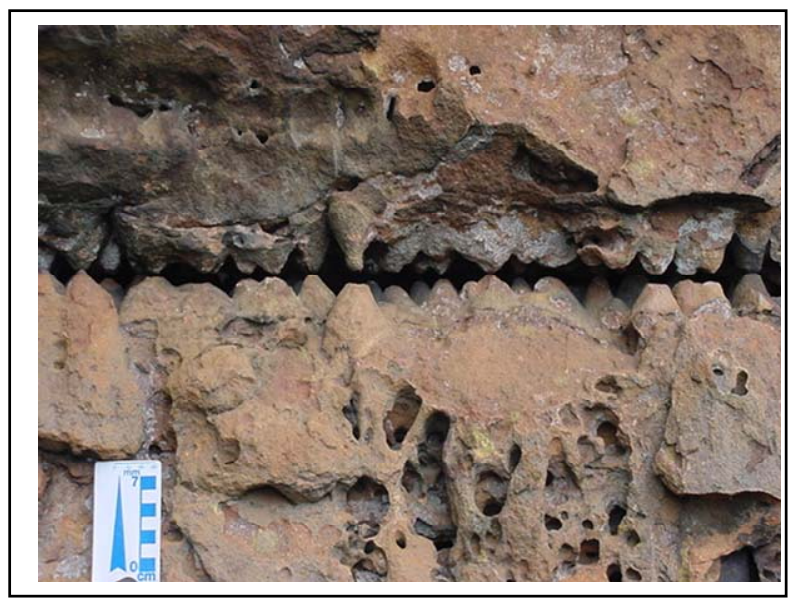

Figura 19: Cones de erosão e túneis anastomosados em contato entre camadas do Arenito Vila Velha, próximo a perfurações atribuíveis a cupins e alvéolos, sugerindo que as feições erosivas maiores possam ter evoluído de túbulos. Parque Estadual de Vila Velha.

\subsection{Perfurações e pinturas rupestres}

Principalmente nas lapas do Arenito Furnas da região dos Campos Gerais existem muitos sítios arqueológicos, com pinturas rupestres atribuíveis às tradições Planalto e Geométrica (Blasi 1972, Chmyz 1976, Prous 1992, Schmitz et al. 1997, Silva et al. 2006, 2007, Parellada 2007). São caracterizadas sobretudo por grafismos em pigmento vermelho. As idades de tais pinturas são muito variáveis, admitindose que possam ter até cerca de 8.000 anos. A presença de pinturas rupestres em torno de perfurações atribuíveis a cupins (figura 17) testemunha que estas últimas já existiam quando da elaboração dos grafismos pelas populações indígenas pré-históricas.

\section{Conclusões}

Qual seria a idade das perfurações de cupins e sua importância relativa no desenvolvimento das feições de relevo típicas da região dos Campos Gerais do Paraná? Estas são perguntas significativas que poderão ser respondidas em estudos mais detalhados e sistemáticos sobre este assunto, usualmente negligenciado nos levantamentos geológicos e geomorfológicos. 
A região dos Campos Gerais apresenta muitas formas de relevo singulares, com importância para a criação de microecossistemas com espécies endêmicas, circulação de águas subterrâneas e formação de paisagens únicas para pesquisas científicas e empreendimentos sustentáveis. Algumas destas feições aparecem associadas a perfurações de cupins, sem que se possa interpretar com segurança qual a influência recíproca entre os processos intempéricos e a atividade orgânica dos cupins.

Por outro lado, a região apresenta muitos sítios arqueológicos, representados sobretudo por abrigos sob rocha com pinturas rupestres, algumas das quais foram elaboradas aproveitando perfurações atribuíveis a cupins. A datação destas pinturas é tarefa árdua, pois os métodos usuais muitas vezes não são aplicáveis. A eventual datação dos túbulos de cupins poderia apoiar a datação das pinturas rupestres da região.

\section{Agradecimentos}

A Luiz Roberto Fontes, pelo estímulo à elaboração deste texto e franquia de bibliografia pertinente. Ao CNPq e Fundação Araucária, pelo suporte às pesquisas que propiciaram as observações aqui relatadas.

\section{Referências}

Ab’Sáber A.N. 1968. O relevo brasileiro e seus problemas. In: Azevedo A. (Coord.), Brasil, a terra e o homem, São Paulo, Cia. Editora Nacional, v.1, p.135-217.

Behling H. 1997. Late Quaternary vegetation, climate and fire history of the Araucaria forest and campos region from Serra Campos Gerais, Paraná State (South Brazil). Review of Palaeobotany and Palynology, Amsterdam, 97:109-121.

Blasi O. 1972. Cultura do índio pré-histórico. Vale do Iapó, Tibagi PR. Arquivos do Museu Paranaense/ Nova Série Arqueologia, Curitiba, n.6, 20p.

Chmyz 1976. Nota prévia sobre o sítio PR PG 1: abrigo sob rocha Cambiju. Estudos Brasileiros, Curitiba, n.2, p.231-246 1976b.

Fontes L.R., Vulcano M.A. 1998. Cupins fósseis do Novo Mundo. In: Fontes, L.R. \& Berti Filho, E. (Eds.), Cupins, o desafio do conhecimento. Piracicaba, FEALQ, p.243-295.

Grassé P.P. 1986. Termitières fossiles et latéritisation. In: Termitologia. Anatomie, physiologie, biologia, systématique des termites. Paris, Masson, v.3, 716p.

Maack R. 1946. Geologia e geografia da região de Vila Velha e considerações sobre a glaciação carbonífera do Brasil. Curitiba, Arquivos do Museu Paranaense, v.5, 305p.

Maack R. 1948. Notas preliminares sobre clima, solos e vegetação do Estado do Paraná. Curitiba, Arquivos de Biologia e Tecnologia, v.II, p.102-200.

Maack R. 1956. Fenômenos carstiformes de natureza climática e estrutural de arenitos do Estado do Paraná. Arquivos de Biologia e Tecnologia, Curitiba, 11: 151-162.

Maack R. 1981. Geografia física do Estado do Paraná. Livraria José Olympio Ed., Rio de Janeiro, 442p.

Machado A.B. 1983a. Radiocarbon dating of some Angolan laterites. In: Melfi, A.J. \& Carvalho, A., Lateritisation processes. II International Seminar on Lateritisation Processes, São Paulo, Proceedings, p.257-260.

Machado A.B. 1983b. The contribution of termites to the formtion of laterites. In: Melfi, A.J. \& Carvalho, A., Lateritisation processes. II International Seminar on Lateritisation Processes, São Paulo, Proceedings, p.261-270.

Machado A.B. 1987. On the origin and age of the Steep Rock Buckshot, Ontario, Canada. Chemical Geology, Amsterdam, 60: 337-349.

Martins É.S., Leonardos O.H. 1992. Estruturas peletais com sulfetos em lateritos resultantes de atividade de termitas. In: Congresso
Brasileiro de Geologia, 37, São Paulo. Bol. Resumos... SBG, p.577-570.

Melo M.S., Moro R.S., Guimarães G.B. (Orgs.). 2007a. Patrimônio natural dos Campos Gerais do Paraná. Ponta Grossa: Editora UEPG, 230p.

Melo,M.S., Guimarães G.B., Ramos A.F.R. Prieto C.C. 2007b. Relevo e hidrografia dos Campos Gerais. In: Melo M.S., Moro R.S., Guimarães G.B. (Org.). Patrimônio natural dos Campos Gerais do Paraná. 1 ed. Ponta Grossa: Editora da UEPG, v. 1, p. 49-58.

Melo M.S. 2006. Formas rochosas do Parque Estadual de Vila Velha. Ponta Grossa: Editora UEPG, 2006. 145p.

Melo M.S. 2009. Aqüífero Furnas: urgência na proteção de mananciais subterrâneos em Ponta Grossa, PR. In: Seminário Internacional "Experiências de Agendas 21 - Desafios do Nosso Tempo". Anais, Curitiba, 2009, 11p. (disponível em http://www.eventos.uepg.br/seminariointernacional/agenda21par ana/trabalho_cientifico/TrabalhoCientifico006.pdf

Melo M.S., Giannini P.C.F. 2007. Sandstone dissolution landforms in the Furnas Formation, southern Brazil. Earth Surface Processes and Landforms, v. 32, p. 2149-2164.

Melo M.S., Guimarães G.B., Pontes H. S., Massuqueto L.L., Pigurim I., Bagatim H.Q., Giannini P.C.F. 2011 Carste em rochas nãocarbonáticas: o exemplo dos arenitos da Formação Furnas, Campos Gerais do Paraná/Brasil e as implicações para a região. Espeleo-Tema, v.22, p.81-97.

Mineropar - Minerais do Paraná do Paraná S/A. 1989. Mapa Geológico do Estado do Paraná: escala 1:650.000. MINEROPAR, Curitiba.

Parellada C.I. 2007. Arqueologia dos Campos Gerais. In: Melo M.S., Moro R.S., Guimarães G.B. (Org.). Patrimônio natural dos Campos Gerais do Paraná. 1 ed. Ponta Grossa: Editora da UEPG, 2007b, v. 1, p. 163-170.

Prous A. 1992. Arqueologia Brasileira. Editora Universidade de Brasília, Brasília, 605p.

Saint-Hilaire A. 1978. Viagem a Curitiba e Província de Santa Catarina. São Paulo, Livraria Itatiaia Editora Ltda., 209p. (tradução de Regina Regis Junqueira).

Schmitz P.I., Silva, A.F., Beber, M.V. 1997. Arqueologia nos cerrados do Brasil Central. In: Serranópolis II, As Pinturas e Gravuras dos Abrigos. São Leopoldo, Instituto Anchietano de Pesquisas/ UNISINOS, 161p.

Silva A.G.C., Parellada C.I., Melo M.S. 2006. Pinturas rupestres em abrigo sob rocha no Sumidouro do Rio Quebra-Perna, Ponta Grossa, PR. Publicatio UEPG, Ciências Exatas e da Terra, Ciências Agrárias e Engenharias, v.12, p.23-31.

Silva A.G.C., Parellada C.I., Melo M.S. 2007. Pinturas rupestres do sítio arqueológico Abrigo Usina São Jorge. Publicatio UEPG. Ciências Exatas e da Terra, Ciências Agrárias e Engenharias, v. 13, p. 25-33.

Soares O. 1989. Furnas dos Campos Gerais, Paraná. Scientia et Labor, Curitiba, 82p. (Editora da UFPR, Série Didática).

Taltasse P. 1957. Les "Cabeças de Jacaré" et le rôle des termites. Revue de Géomorphologie Dynamique 8: 166-170.

Téssier F. 1959. Termitières fossiles dans la latérite de Dakar, Sénégal. Remarques sur les structures latéritiques. Annales de la Faculté des Sciences de l’Université de Dakar 4: 91-132.

Wray R.A.L. 1997. A global review of solutional weathering forms on quartz sandstones. Earth-Science Reviews 42: 137-160. . ${ }^{\text {i }}$

Recebido 18 de setembro de 2013 Aceito 04 de dezembro de 2013 